\title{
Chronic fatigue report delayed as row breaks out over content
}

Lynn Eaton BMJ

The government's long awaited report on the treatment of chronic fatigue syndrome could be in jeopardy after four key members resigned from the working group.

The move throws doubt on the validity of the report, which was due to be published in the first week of January. As the $B M J$ went to press, the chief medical officer, Liam Donaldson, had postponed its launch on 4 January 2002.

A total of 10 people from the original working group have resigned for various reasons since it was set up in 1998. The most recent resignations were highlighted in a written question by the Countess of Mar to health minister Lord Hunt on 17 December.

Two psychiatrists, a public health doctor, and a nurse thera- pist have resigned, saying that the report plays down the psychological and social aspects of the condition and concentrates on a medical model. Two patients are understood to have also resigned recently.

The group was set up to consider how best the NHS could care for people with the syndrome, also known as myalgic encephalomyelitis or "ME."

But with so little still known about what causes the syndrome how to diagnose it, and how best to treat it, it is understood that the report fails to provide the straightforward answers doctors may have hoped for.

"I wanted something less subjective and more evidence based," said one dissenter, who did not want to be named.
The working group, which consists of patients and professionals, has grappled to encompass the views of both groups in the final report.

"There have been a lot of contentious issues," admitted Chris Clark of Action for ME. "But there was a huge amount of central ground."

One of the most contentious issues is the inclusion of "pacing" as one method for managing the condition. This involves monitoring levels of energy and activity each day, not overstretching yourself, and adjusting your lifestyle. There has been little research to substantiate the theory. Some clinicians believe it could perpetuate the condition, although others endorse it.

Pacing is given equal status to graded exercise and cognitive behavioural therapy, both of which have been reviewed as having "promising results."

Some professionals believe that patients may be reluctant to accept treatments such as cognitive therapy, which could be seen as a treatment for a psychiatric problem. Meanwhile many patients are concerned that some professionals still see the syndrome as being "all in the mind."

"No one believes chronic fatigue syndrome is simply a psychological condition," said psychiatrist Dr Peter White of St Bartholomew's Hospital, London, one of those who resigned from the group. "But all the evidence suggests it is biopsychosocial. The condition has both physical and mental factors." $\square$

\section{WHO calls for new pact on health care}

Lynn Eaton BMJ

A massive injection of Western aid to developing countries not only will improve standards of health but will boost the overall global economy, a new commission set up by the World Health Organization has said.

The Commission on Macroeconomics and Health, chaired by Harvard professor Jeffrey Sachs (see interview on $p$ 12), has put forward radical proposals for a health pact between donor countries in the West and developing countries. The commission has proposed that higher income countries should increase their existing donation of about $\$ 6 \mathrm{bn}$ (£4.29bn; €6.8bn) a year to reach $\$ 22$ bn a year by 2007 and $\$ 31$ bn a year by 2015 .

Currently, the target for
United Nations' overseas aid (which includes some donation to health but will also cover roads, education, and other projects) is $0.7 \%$ of gross domestic product, but the United Kingdom gives only $0.26 \%$ and the United States less than $0.1 \%$.

The burden of disease in some low income regions, such as the impact of AIDS in Africa, may undermine the development of such countries in the next generation, the report argued.

Life expectancy at birth in sub-Saharan Africa is only 51 years compared with 78 years in higher income countries.

"To reduce these staggeringly high mortality rates, the control of communicable diseases and improved maternal and child health remain the highest public health priorities," said the report.

Professor Sachs argued that by increasing the standard of health it should be possible to increase the economic growth of a country, helping to break down the poverty trap.

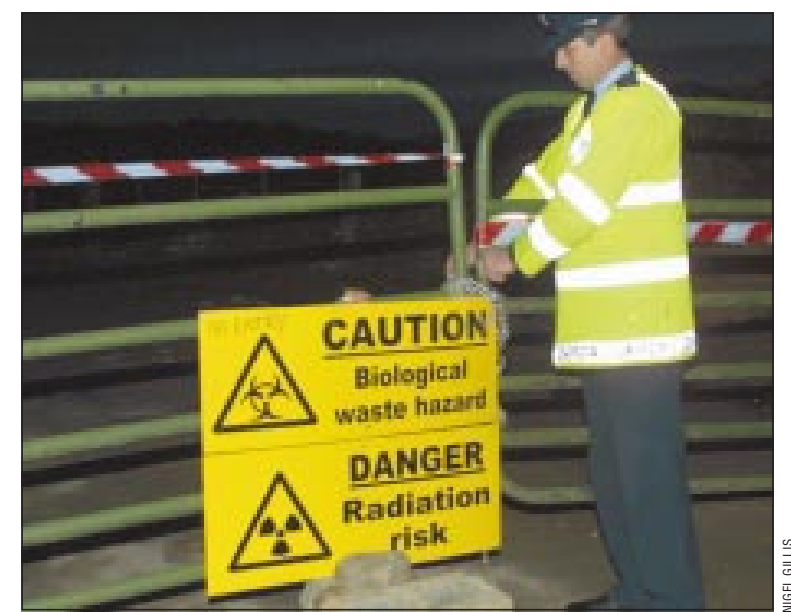

Local councils across the Republic of Ireland are scrambling to find out if they have sites containing improperly dumped hospital waste after officials in both County Wicklow and Dublin confirmed finding extensive illegal dumps reportedly containing hundreds of thousands of tonnes of material, including hospital waste, in the past month and a half. To date, colostomy bags, used intravenous tubing, swabs, Petrie dishes, sample bottles, blood bags, sharps-including surgical blades-and bloody bandages have turned up.

Doug Payne Dublin 